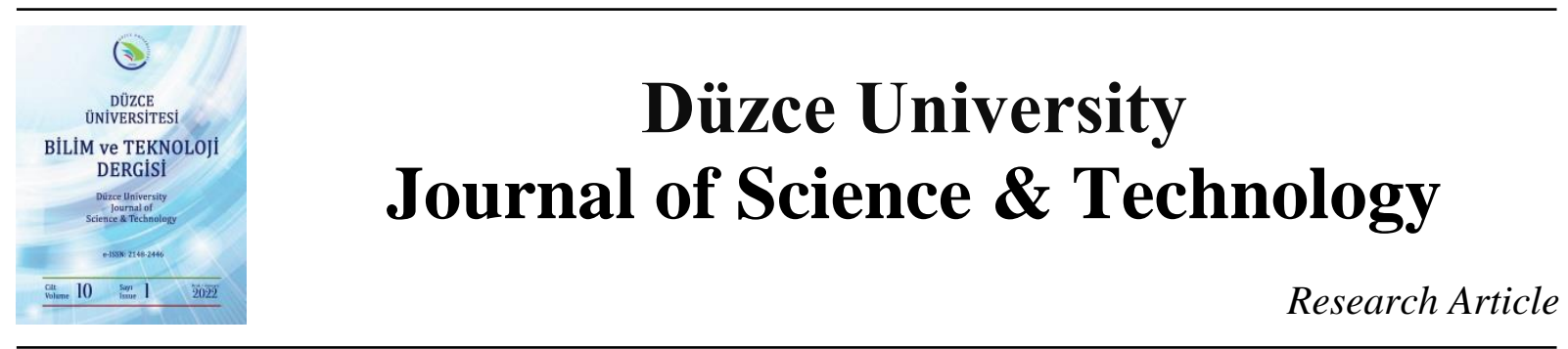

\section{Single-phase Boost-type Active Tracking AC-AC Voltage Regulator with an Improved Hybrid Control Technique}

\author{
(D) Faruk YALÇIN ${ }^{\mathrm{a}, *}$, (D) Felix A. HIMMELSTOSS ${ }^{\mathrm{b}}$ \\ ${ }^{a}$ Department of Mechatronics Engineering, Faculty of Technology, Sakarya University of Applied Sciences, \\ Sakarya, TURKEY \\ ${ }^{b}$ Department of Electronic Engineering, University of Applied Sciences Technikum Wien, Vienna, AUSTRIA \\ * Corresponding author's e-mail address: farukyalcin@sakarya.edu.tr
}

DOI:10.29130/dubited.923414

\begin{abstract}
This paper presents a switch-mode single-phase boost-type AC-AC voltage regulator. The topology of the regulator needs only reduced numbers of components. Unlike the similar studies in the literature, a new hybrid control technique with a closed-loop PID controller and a novel developed feedforward controller is applied to the regulator that enhances the active tracking of the reference output voltage to obtain a higher quality of the sine-wave output voltage, when the input AC voltage is an ideal pure sine or including different harmonics levels. The proposed regulator with the proposed control technique is tested both by simulation and experimentally. The experimental set-up for the regulator is designed for $0.75 \mathrm{~kW}$ output power, $0-100 \mathrm{Vp}$ input voltage $(50 \mathrm{~Hz})$, and $0-200 \mathrm{Vp}$ output voltage. The results have shown that the proposed switch-mode boost type regulator is capable of obtaining the desired $\mathrm{AC}$ voltage with harmonics lower than 5\% THD (total harmonic distortion) for different input/output parameters and different load conditions.
\end{abstract}

Keywords: Boost converter, AC-AC regulator, Single-phase, Active tracking, Harmonics

\section{İyilişetirilmiş Hibrit Kontrol Tekniği ile Tek Faz Yükseltici Tip Aktif İzleyen AA-AA Gerilim Regülatörü}

\begin{abstract}
$\underline{\mathrm{O} Z}$
$\mathrm{Bu}$ çalışmada anahtarlamalı mod tek faz yükseltici tip bir AA-AA gerilim regülatörü sunulmuştur. Literatürdeki benzer çalışmalardan farklı olarak, çıkışta yüksek kalitede sinüs formunda gerilim elde edebilmek için referans çıkış geriliminin takibini iyileştiren yeni bir hibrit kontrol tekniği regülatör çalışmasını kontrol için uygulanmıştır. Bu hibrit kontrol tekniğinde, kapalı çevrim PID kontrol yöntemi yeni geliştirilen ileri beslemeli açık çevrim kontrolcü ile desteklenmiş̧ir. Önerilen çevirici ile önerilen kontrol tekniği hem simülasyon olarak hem de deneysel olarak test edilmiştir. Elde edilen sonuçlar, önerilen regülatörün farklı çalışma çalışma şartlarında üstünlügünü göstermiştir.
\end{abstract}

Anahtar Kelimeler: Yükseltici çevirici, AA-AA regülatörü, Tek faz, Aktif izleyen, Harmonik 


\section{INTRODUCTION}

Power quality is becoming a major problem for AC consumers continuously depending on the increasing demand for electrical power. AC devices require an alternating supply voltage with a magnitude band, this band is very narrow for some sensitive devices. Voltage sag/swell effects in the distribution systems occurring at the different loading levels are the mostly mentioned problems for the AC consumers. On the other hand, some AC consumers may demand variable voltage magnitudes different from the grid voltage levels. So, AC voltage regulation is one of the major concerns for the researchers in the literature and many kinds of solutions are proposed by the researchers.

FACTS devices such as DVRs (dynamic voltage restorers) [1,2], voltage conditioners [3,4], voltage sag supporters [5,6], and voltage sag/swell compensators [7,8] are used for regulation of the voltage variations in distribution systems. These devices provide the desired distribution network voltage to the consumers which are connected to the distribution buses. So, independent voltage regulation for each end-user is not possible in this way. Also, these FACTS-based regulators are structured by a coupling transformer with a VSI (voltage source inverter). VSIs which are used in these FACTS devices may be either a DC-AC converter or an AC-DC-AC converter. DC-AC converter-based VSIs require independent external DC storage systems, such as capacitors or batteries. So, DC-AC converter-based VSIs cannot meet efficient compensation of voltage sags/swells for long durations. On the other hand, the compensation capabilities are limited, depending on the capacities of the external storage units. AC-DC-AC based converters do not need external storage systems as they have an AC-DC sub-unit in their structures. In spite of this advantage, the additional AC-DC stage of the AC-DC-AC converters increases the losses of the FACTS devices.

Standalone AC-DC-AC based VSIs can be used for voltage regulation for AC consumers instead of the FACTS-based regulators $[9,10]$. This solution is less complex as there is no need for a coupling transformer. Also, voltage regulation for each individual consumer can be provided independently. But, an additional AC-DC stage for AC-AC conversion still increases the total loss.

Because of the mentioned complexity and other disadvantages of the FACTS devices-based regulators and direct VSI applications, direct AC-AC conversion becomes more efficient. In the literature, many kinds of AC-AC regulators are developed. The traditional AC-AC PWM choppers are the basic regulators for AC-AC regulation [11]. But these regulators produce alternating voltages at the output with high-level harmonics. So, they need additional filtering units, such as passive filters or coupling transformers. In recent years, switch-mode buck [12,13], boost [14,15], and buck-boost [16,17] type $\mathrm{AC}-\mathrm{AC}$ regulators were developed for $\mathrm{AC}$ regulation. The switch-mode structures of these regulators provide close to sine-wave output voltages with low harmonics levels without the need for additional filtering units. The topology structures are also less complex in these regulators. Although the mentioned switch-mode AC-AC regulators are applied for $\mathrm{AC}$ regulations in the literature successfully, the main lack of these studies is the absence of applying input AC voltages including harmonics. The similar existing studies in the literature are only interested in the application of the pure sine-wave input $\mathrm{AC}$ voltage. But in practice, many $\mathrm{AC}$ consumers are supplied with sine-wave voltages including higher harmonics, because of the distortions in the mains AC power networks. In this case, harmonic elimination is also needed as is the AC voltage regulation. This is so important as the AC customers must be supplied with a high-quality sine-wave voltage with less than 5\% THD [18].

In this paper, a single-phase boost-type active tracking AC-AC voltage regulator is developed. For the active tracking of the desired reference output sine-wave voltage, an improved control technique is developed. The proposed regulator topology and the control technique are patented by the co-author of this paper [19]. The proposed regulator topology includes reduced numbers of components, just four active switches, one inductor, and one capacitor compared to the similar boost AC-AC regulator studies for [14] and [15] (Four active switches, two inductors, two capacitors and one transformer are required for [14]. Eight active switches, one inductor and three capacitors are required for [15]). The 
boost-type structure of the proposed regulator provides a wide range of output voltage amplitude higher than the input voltage amplitude. Unlike similar studies in the literature, the proposed control technique is structured as a new hybrid control method with a closed-loop PID controller and a new feedforward controller. Thus, active tracking of the reference sine-wave output voltage is enhanced to obtain ideally close to sine-wave output voltage, when the input voltage is a pure sine or is including harmonics. The proposed regulator with the proposed control technique is tested both by simulation and experimentally. The results have shown that the proposed switch-mode boost type regulator is capable of obtaining a desired AC voltage with harmonics lower than 5\% THD for different input/output parameters and different load conditions.

\section{THE PROPOSED SINGLE-PHASE BOOST AC-AC REGULATOR}

This section presents the proposed single-phase boost-type AC-AC regulator topology, the operation procedure of the regulator, and the dynamic analysis of the regulator topology.

\section{A. THE TOPOLOGY}

The main circuit of the proposed single-phase boost-type AC-AC regulator is shown in Figure 1 [19].

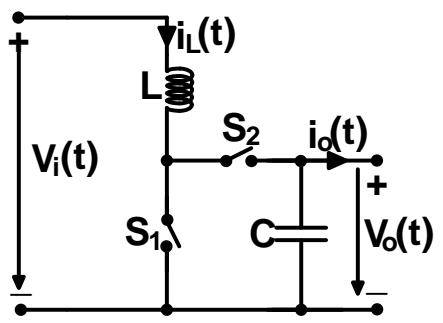

Figure 1. General topology of the proposed single-phase boost-type AC-AC regulator

In Figure $1, \mathrm{~V}_{\mathrm{i}}, \mathrm{V}_{\mathrm{o}}, \mathrm{L}$, and $\mathrm{C}$ represent input $\mathrm{AC}$ voltage, output $\mathrm{AC}$ voltage, inductor and capacitor, respectively. $S_{1}$ and $S_{2}$ are the bidirectional active switches. These active switches are composed of MOSFETs in this study. So, the proposed regulator circuit with MOSFETs can be shown in Figure 2.

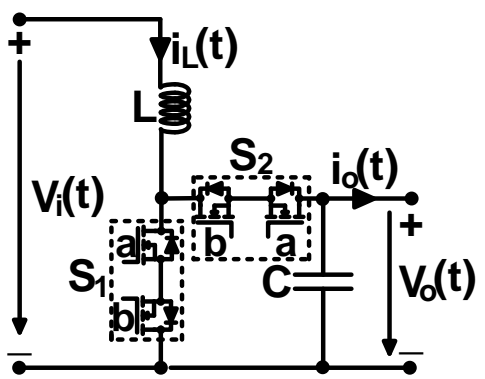

Figure 2. Proposed single-phase boost-type AC-AC regulator with MOSFETS

\section{B. THE OPERATION PROCEDURE}

The operation procedure of the proposed single-phase AC-AC regulator is based on the well-known traditional boost converter. Depending on the PWM duty ratio (d) control of $S_{1}$, the applied input voltage $\mathrm{V}_{\mathrm{i}}(\mathrm{t})$ is boosted to $\mathrm{V}_{\mathrm{o}}(\mathrm{t})$ at the output. So, the output voltage is obtained as an AC voltage with the same polarity of the input voltage, but with higher amplitude value than of the input. $S_{2}$ is the supplementary switch of $S_{1}$. When $S_{1}$ is turned on, $S_{2}$ is turned off. In this stage, $V_{i}$ supplies the 
inductor and the pre-energized capacitor supplies the output load. When $S_{1}$ is turned off, $S_{2}$ is turned on. In this stage, $\mathrm{V}_{\mathrm{i}}$ supplies the inductor, the capacitor, and the output load.

As the input voltage $V_{i}$ is an alternating voltage, the polarity of $V_{i}$ changes in each half period. So, the states of the sub-active switches of the bidirectional active switches $S_{1}$ and $S_{2}$ change depending on the kind of the half-period of the input voltage. Table 1 summarizes the control of the active switches $S_{1}$ and $\mathrm{S}_{2}$.

Table 1. Control signal of MOSFETs used in Figure 2 as part of AC-switches $S_{1}$ and $S_{2}$.

\begin{tabular}{|c|c|c|c|c|c|c|c|c|}
\hline \multirow{3}{*}{ State } & \multicolumn{4}{|c|}{$S_{1}$} & \multicolumn{4}{|c|}{$\mathbf{S}_{2}$} \\
\hline & \multicolumn{2}{|c|}{$\begin{array}{c}\text { Positive Half-Wave } \\
\text { Stage }\end{array}$} & \multicolumn{2}{|c|}{$\begin{array}{l}\text { Negative Half- } \\
\text { Wave Stage }\end{array}$} & \multicolumn{2}{|c|}{$\begin{array}{c}\text { Positive Half-Wave } \\
\text { Stage }\end{array}$} & \multicolumn{2}{|c|}{$\begin{array}{c}\text { Negative Half } \\
\text { Wave Stage }\end{array}$} \\
\hline & $\mathbf{S}_{1 \mathrm{a}}$ & $\mathbf{S}_{\mathbf{1 b}}$ & $\mathbf{S}_{1 \mathrm{a}}$ & $\mathbf{S}_{1 \mathrm{~b}}$ & $\mathbf{S}_{2 \mathbf{a}}$ & $\mathbf{S}_{2 \mathrm{~b}}$ & $\mathbf{S}_{2 \mathrm{a}}$ & $S_{2 b}$ \\
\hline ON & on & off & off & on & off & on & on & off \\
\hline OFF & off & off & off & off & off & off & off & off \\
\hline
\end{tabular}

The switching pattern of the MOSFETs are shown in Figure 3.

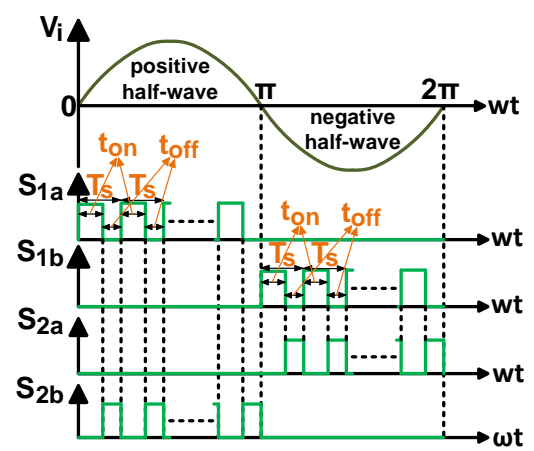

Figure 3. Switching pattern of the MOSFETs

In Figure 4, the equivalent sub-circuits of the proposed regulator topology given in Figure 2 are shown depending on the control of the active switches for one cycle sine-wave input voltage.

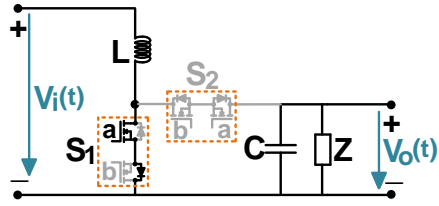

(a)

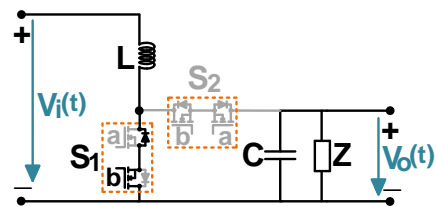

(c)

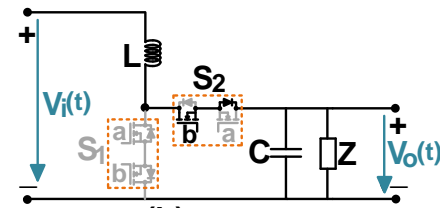

(b)

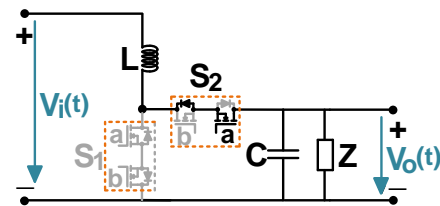

(d)

Figure 4. Equivalent sub-circuits of the proposed boost type regulator (a) Positive half-wave output stage, on mode ( $S_{1}$ is on, $S_{2}$ is off), (b) Positive half-wave output stage, off mode ( $S_{1}$ is off, $S_{2}$ is on), (c) Negative half-wave output stage, on mode ( $S_{1}$ is on, $S_{2}$ is off), (d) Negative half-wave output stage, off mode ( $S_{1}$ is off, $S_{2}$ is on)

The voltage producing operation of the proposed regulator for one cycle of output voltage can be determined as a combination of Figure 3 and Figure 4 to the two main stages as follows. 
Stage $1(0 \leq w t<\pi)$ : In this stage, input voltage is the positive half-wave. During PWM on-stage of $\mathrm{S}_{1}$ ( $\mathrm{S}_{2}$ is off), $\mathrm{S}_{1 \mathrm{a}}$ is turned on, $\mathrm{S}_{1 \mathrm{~b}}$ is turned off and both $\mathrm{S}_{2 \mathrm{a}}$ and $\mathrm{S}_{2 \mathrm{~b}}$ are turned off. During PWM off-stage of $S_{1}\left(S_{2}\right.$ is on), both $S_{1 a}$ and $S_{1 b}$ are turned off, $S_{2 a}$ is turned off, and $S_{2 b}$ is turned on. Depending on the continuously proper control of $d$ that is the PWM duty ratio of $S_{1}$, the positive half sine-wave desired output voltage is produced from the input voltage.

Stage $2(\pi \leq w t<2 \pi)$ : In this stage, input voltage is the negative half-wave. During PWM on-stage of $\mathrm{S}_{1}$ ( $S_{2}$ is off), $S_{1 b}$ is turned on, $S_{1 a}$ is turned off and both $S_{2 a}$ and $S_{2 b}$ are turned off. During PWM off-stage of $S_{1}\left(S_{2}\right.$ is on), both $S_{1 a}$ and $S_{1 b}$ are turned off, $S_{2 a}$ is turned on, and $S_{2 b}$ is turned off. Depending on the continuously proper control of $d$ that is the PWM duty ratio of $S_{1}$, the negative half sine-wave desired output voltage is produced from the input voltage.

\section{THE DYNAMIC ANALYSIS}

In this section, the detailed dynamic analysis of the proposed single-phase boost-type AC-AC regulator is given. In the analysis, real parasitic effects of the elements used in the topology are taken into account, in order to provide accurate analysis for real-time applications.

The equivalent circuit of the proposed regulator for positive half-wave input stage is shown in Figure 5. In the equivalent circuit, it is assumed that the selected MOSFETs are the same.

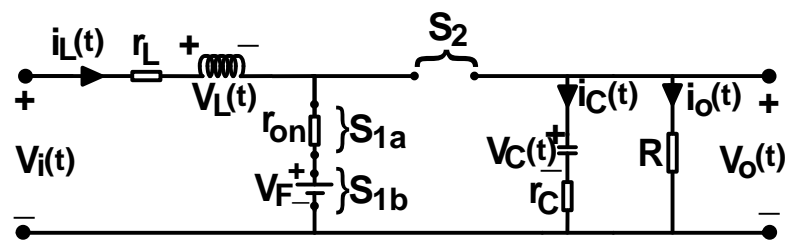

(a)

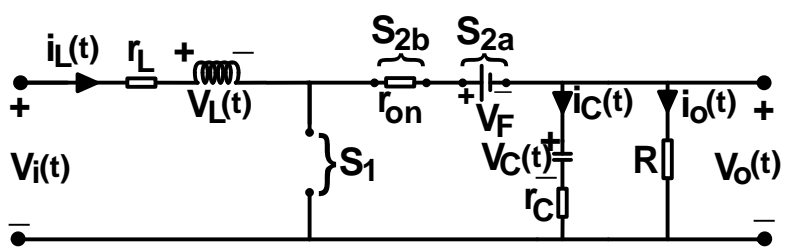

(b)

Figure 5. Positive half-wave stage equivalent circuit of the regulator (a) on-mode- $S_{1}$ is turned on and $S_{2}$ is turned off, (b) off-mode $-S_{1}$ is turned off and $S_{2}$ is turned on

In Figure 5, $i_{o}, i_{L}, i_{C}, V_{L}, V_{C}, V_{F}, r_{o n}, r_{L}, r_{C}$, and $R$ represent the output current, inductor current, capacitor current, inductor voltage, capacitor voltage, forward biasing voltage of the MOSFET's antiparallel diode, on-resistance of the MOSFET, equivalent series resistance (ESR) of the inductor, ESR of the capacitor, and output load resistance, respectively.

The dynamic analysis of the regulator can be achieved from Figure 5 for positive half-wave input stage. The dynamic equations of the state variables that are the inductor current and the output voltage are derived for the on-mode and the off-mode as seen in Figure 5.

On-mode ( $S_{1}$ is on and $S_{2}$ is off): The state equations for the inductor current and the output voltage for this mode can be derived from Figure $5 a$ according to

$$
\frac{d i_{L}(t)}{d t}=-\frac{1}{L}\left(r_{L}+r_{o n}\right) i_{L}(t)+\frac{1}{L}\left[V_{i}(t)-V_{F}\right]
$$


$\frac{d V_{o}(t)}{d t}=-\frac{1}{\left(R+r_{C}\right) C} V_{o}(t)$.

Off-mode ( $S_{1}$ is off and $S_{2}$ is on): The state equations for the inductor current and the output voltage for this mode can be derived from Figure $5 b$ according to

$$
\begin{aligned}
& \frac{d i_{L}(t)}{d t}=-\frac{1}{L}\left(r_{L}+r_{o n}\right) i_{L}(t)-\frac{1}{L} V_{o}(t)+\frac{1}{L}\left[V_{i}(t)-V_{F}\right] \\
& \frac{d V_{o}(t)}{d t}=\left(\frac{R}{R+r_{C}}\right)\left[\frac{1}{C}-\frac{r_{C}}{L}\left(r_{L}+r_{o n}\right)\right] i_{L}(t)-\left(\frac{R}{R+r_{C}}\right)\left(\frac{r_{C}}{L}+\frac{1}{R C}\right) V_{o}(t)+\frac{r_{C} R}{\left(R+r_{C}\right) L}\left[V_{i}(t)-V_{F}\right] .
\end{aligned}
$$

The equation of the state-space model for on-mode can be obtained by (1) and (2) to

$$
\left[\begin{array}{c}
i_{L}(t) \\
V_{o}(t)
\end{array}\right]=\left[\begin{array}{cc}
-\frac{1}{L}\left(r_{L}+r_{o n}\right) & 0 \\
0 & -\frac{1}{\left(R+r_{C}\right) C}
\end{array}\right]\left[\begin{array}{c}
i_{L}(t) \\
V_{o}(t)
\end{array}\right]+\left[\begin{array}{cc}
\frac{1}{L} & -\frac{1}{L} \\
0 & 0
\end{array}\right]\left[\begin{array}{c}
V_{i}(t) \\
V_{F}
\end{array}\right] .
$$

The equation of the state-space model for off-mode can be obtained by (3) and (4) as follows,

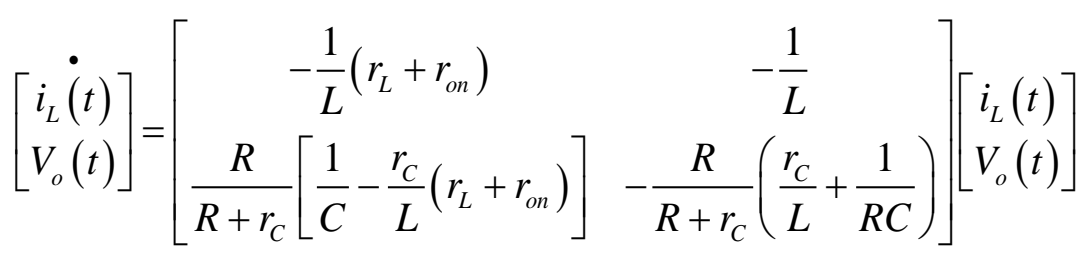

$$
\begin{aligned}
& +\left[\begin{array}{cc}
\frac{1}{L} & -\frac{1}{L} \\
\frac{R}{R+r_{C}} \frac{r_{C}}{L} & -\frac{R}{R+r_{C}} \frac{r_{C}}{L}
\end{array}\right]\left[\begin{array}{l}
V_{i}(t) \\
V_{F}
\end{array}\right]
\end{aligned}
$$

As explained before, the above dynamic analysis is done for the positive half-wave input case. Similarly, if a dynamic analysis is done for the negative half-wave input case, the same state-space equations (5) and (6) are derived. So, the state-space equations (5) and (6) are also valid for all input cases.

Thus, the small signal transfer function between the output voltage and the PWM duty ratio can be derived from (5) and (6) according to

$$
G_{b o o s t}(s)=\frac{\hat{V_{o}}(s)}{d(s)}=\frac{g s+(a g+c f)}{s^{2}+(a+e) s+(a e-b c)} .
$$

The coefficients used in (7) can be given as

$$
a=\frac{\left(r_{L}+r_{o n}\right)}{L}
$$


$b=-\frac{(1-\bar{D})}{L}$

$c=\frac{(1-\bar{D}) R}{R+r_{C}}\left[\frac{1}{C}-\frac{r_{C}}{L}\left(r_{L}+r_{o n}\right)\right]$

$e=\frac{(1-\bar{D}) R}{R+r_{C}} \frac{r_{C}}{L}+\frac{1}{\left(R+r_{C}\right) C}$

$f=\frac{\bar{V}_{o}}{L}$

$g=-\frac{R}{R+r_{C}}\left[\frac{1}{C}-\frac{r_{C}}{L}\left(r_{L}+r_{o n}\right)\right] \overline{i_{L}}+\frac{R}{R+r_{C}} \frac{r_{C}}{L}\left[\bar{V}_{o}-\bar{V}_{i}+V_{F}\right]$.

In (9)-(13), $\bar{D}, \bar{i}_{L}, \bar{V}_{o}$, and $\bar{V}_{i}$ represent the values of the PWM duty ratio, the inductor current, the output voltage, and the input voltage respectively at the operating point. $\bar{V}_{o}$ and $\overline{i_{L}}$ can be formulated as below

$$
\bar{V}_{o}=\frac{\bar{V}_{i}}{(1-\bar{D})}, \quad \bar{i}_{L}=\frac{\bar{V}_{i}}{(1-\bar{D})^{2} R} .
$$

\section{THE PROPOSED HYBRID CONTROL TECHNIQUE}

This section presents the proposed hybrid control technique that is used for the control of the proposed $\mathrm{AC}-\mathrm{AC}$ regulator. The general control diagram of the proposed regulator can be seen in Figure 6.

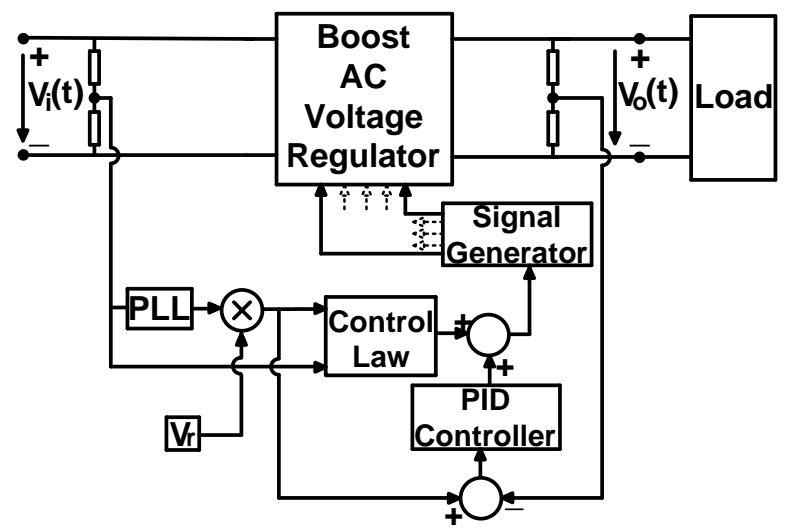

Figure 6. General control diagram of the proposed regulator

In Figure 6, the PLL determines the frequency of the input AC voltage and $\mathrm{V}_{\mathrm{r}}$ defines the magnitude of the reference output AC voltage. Thus, the desired sine-wave reference output voltage can be derived as 


$$
V_{r e f}(w t)=V_{r} \sin w t .
$$

As shown in Figure 6, the proposed hybrid controller is structured by two main units. One of these units is the traditional PID controller. The PID controller has to eliminate the error between the real output voltage and the reference output voltage by satisfying the response performance depending on the design criteria. The other unit of the hybrid controller is the new developed feedforward controller and it is called as "control law (CL)" in Figure 6. The CL is an open-loop controller that produces a PWM duty ratio depending on the topology parameters as can be seen below.

$$
d_{C L}(w t)=\sqrt{\frac{2 L\left|V_{r} \sin w t\right|^{2}\left(\left|V_{r} \sin w t\right|-\left|V_{i}(w t)\right|+V_{F}\right)}{\left|V_{i}(w t)\right|\left|V_{r} \sin w t\right|\left(\left|V_{i}(w t)\right|-V_{F}\right) T_{S} R}}
$$

In (16), $\mathrm{T}_{\mathrm{S}}$ represents the PWM switching period. The PWM duty ratio of the CL in (16) cannot directly meet the desired PWM duty ratio for obtaining the reference output voltage. But it can produce a duty ratio close to the real duty ratio. As seen from (16), the duty ratio produced by the CL has a static structure and it can be produced in a fast manner. Thus, the CL supports the PID controller to obtain the desired duty ratio with an improved response performance. So, the proposed hybrid control technique provides accurate and efficient active tracking of the reference output voltage in order to obtain close to sine-wave output voltage with low THD. As a result, the desired PWM duty ratio is obtained by the PID controller and the CL

$$
d(w t)=d_{P I D}(w t)+d_{C L}(w t) .
$$

The signal generator is the switch control sub-algorithm of the digital controller. It produces the switches signals depending on the determined duty ratio and the switching pattern logic given in Figure 3.

In this study, discrete time control is used for the regulator operation control. So, the control block diagram of the regulator based on the proposed hybrid control technique can be shown in Figure 7.

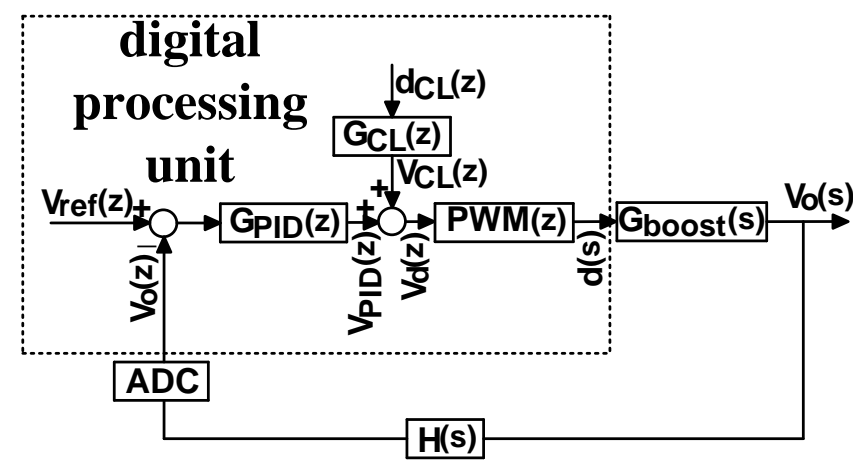

Figure 7. Discrete-time control block diagram based on the proposed hybrid control technique for the boosttype regulator

From Figure 7, the major relations between the control signals and the transfer functions of the discrete time control block diagram can be given as below.

$$
\begin{aligned}
& G_{C L}(z)=\frac{1}{P W M(z)} \\
& V_{d}(z)=V_{C L}(z)+V_{P I D}(z)
\end{aligned}
$$




$$
d(z)=V_{d}(z) \cdot P W M(z)
$$

The transfer function of the discrete PID controller is determined in the study as

$$
G_{P I D}(z)=K_{P}+K_{I} \frac{z}{z-1}+K_{D} \frac{z-1}{z}
$$

\section{THE RESULTS}

In this section, the design steps of the proposed regulator and the results of both the simulation and the experimental tests for the regulator are given.

\section{A. THE DESIGN PARAMETERS}

For the real-time experimental application of the proposed regulator, a laboratory set-up is designed. The set-up is designed for $0.75 \mathrm{~kW}$ output power, 0-100 Vp input voltage $(50 \mathrm{~Hz})$, and $0-200 \mathrm{Vp}$ output voltage. IXFK98N50P3 type n-channel, high-speed, low on-resistance MOSFETs $\left(\mathrm{V}_{\mathrm{DSS}}=500\right.$ $\mathrm{V}, \mathrm{r}_{\mathrm{on}}=50 \mathrm{~m} \Omega, \mathrm{I}_{\mathrm{D}}=98 \mathrm{~A}, \mathrm{~V}_{\mathrm{F}}=1.5 \mathrm{~V}$ ) are used in the set-up circuit. The determined values of the switching frequency, the inductor and the capacitor for the regulator circuit are given in Table 2.

Table 2. The selected values of the inductor, capacitor and the switching frequency.

\begin{tabular}{ccccc}
\hline $\begin{array}{c}\text { Switching } \\
\text { Frequency } \mathbf{f}_{\mathbf{s}}\end{array}$ & \multicolumn{2}{c}{ Capacitor } & \multicolumn{2}{c}{ Inductor } \\
\cline { 2 - 5 }$(\mathrm{kHz})$ & $\mathbf{C}$ & $\mathbf{r}_{\mathbf{C}}$ & $\mathbf{L}$ & $\mathbf{r}_{\mathbf{L}}$ \\
\hline 50 & 4.7 & $(\mathrm{~m} \Omega)$ & $(\mu H)$ & $(\mathrm{m} \Omega)$ \\
\hline
\end{tabular}

The determined operating point parameters that are used in the discrete time PID controller design are given in Table 3.

Table 3. The operating point parameters of the regulator.

\begin{tabular}{cccc}
\hline$\overline{\mathbf{V}}_{\mathbf{i}}$ & $\overline{\mathbf{D}}$ & $\overline{\mathbf{V}}_{\mathbf{o}}$ & $\mathbf{R}$ \\
$(V)$ & 0.5 & $(V)$ & $(\Omega)$ \\
\hline 40 & 80 & 60 \\
\hline
\end{tabular}

The parameters of the PID controller used in (21) are obtained through the optimum design and performance analysis in MATLAB-Sisotool as can be seen below

$$
K_{P}=-0.713, \quad K_{I}=0.098, \quad K_{D}=0.0624 .
$$

\section{B. THE SIMULATION TESTS}

The simulation tests are applied to the proposed converter with the proposed hybrid control technique in order to verify the theoretical results of the study.

Three different simulation test cases given in Table 4 are applied to the regulator system in MATLAB Simulink. The simulation wave form test results are given in Figures 8-10. The detailed numerical results of the output for the simulation tests are given in Table 5. In Table 5, THD $\mathrm{V}$ and $\mathrm{THD}_{\mathrm{I}}$ represent the voltage THD, and the current THD, respectively. 
As seen from Figures 8-10 and Table 5, the proposed single-phase boost-type AC-AC regulator is capable of obtaining the desired reference AC sine-wave voltages as close as possible with low THD levels under 5\%, even if the input AC voltages have harmonics. So, the wave form results in Figures 8-10 and the numerical results in Table 5 prove that the proposed hybrid control technique is accurate and efficient for the active tracking of the reference output voltages.

Table 4. Test cases for the simulation tests.

\begin{tabular}{cccc}
\hline $\begin{array}{c}\text { Test } \\
\text { Cases } \\
\text { No }\end{array}$ & $\mathbf{V}_{\mathbf{i}}$ & Output Load $\mathbf{Z}$ & $\begin{array}{c}\text { Desired output } \\
\text { fundamental sine-wave } \\
\text { voltage } \mathbf{V}_{\mathbf{o}} \\
(\mathrm{V})\end{array}$ \\
\hline 1 & 50V sine + HOH $(\mathrm{f}=50 \mathrm{~Hz})$ & Resistive $\mathrm{R}=22 \Omega$ & 110 \\
\hline 2 & 30V sine + fluct. $(\mathrm{f}=50 \mathrm{~Hz})$ & Inductive $\mathrm{R}=6 \Omega, \mathrm{L}=1 \mathrm{mH}$ & 80 \\
\hline 3 & 40V sine + $\mathrm{LOH}(\mathrm{f}=50 \mathrm{~Hz})$ & Capacitive $\mathrm{R}=5 \Omega, \mathrm{C}=0.5 \mathrm{mF}$ & 75 \\
\hline fluct.: fluctuations, $\mathrm{HOH}$ : high order harmonics, $\mathrm{LOH}:$ low order harmonics & \\
\hline
\end{tabular}

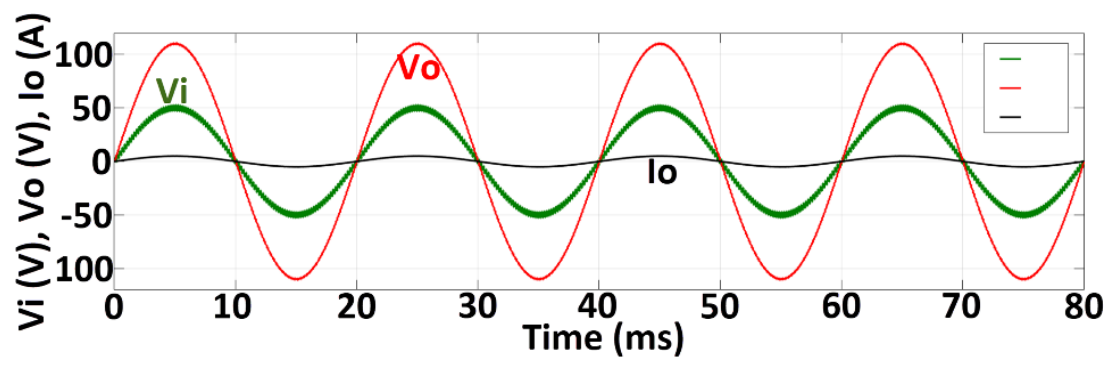

Figure 8. The simulation results for the test case-1

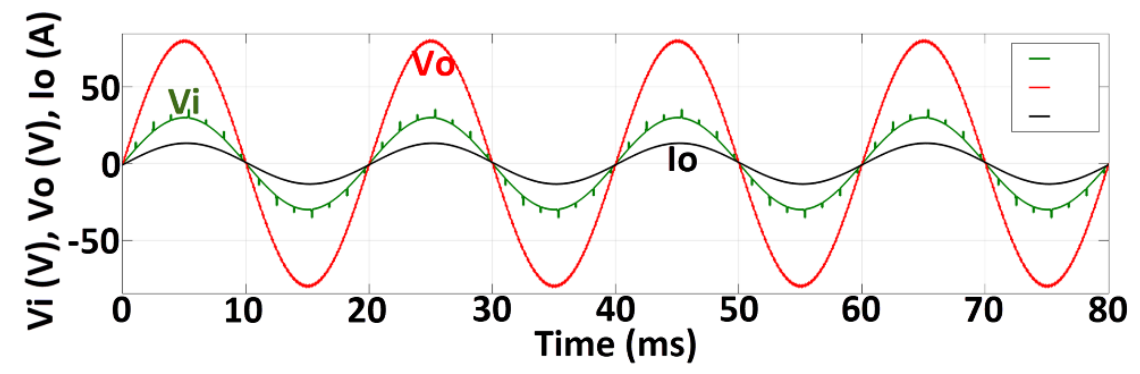

Figure 9. The simulation results for the test case-2

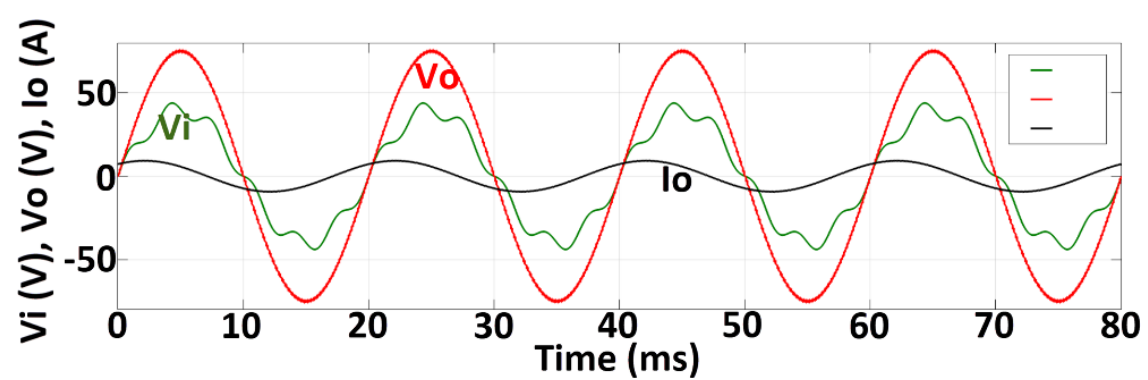

Figure 10. The simulation results for the test case-3 
Table 5. The achieved numerical simulation results of the test cases

\begin{tabular}{cccc}
\hline Test Case No & $\begin{array}{c}\text { Obtained Fundamental } \mathbf{V}_{\mathbf{~}} \\
(V)\end{array}$ & $\begin{array}{c}\mathbf{T H D}_{\mathbf{V}} \\
(\%)\end{array}$ & $\begin{array}{c}\mathbf{T H D}_{\mathbf{I}} \\
(\%)\end{array}$ \\
\hline 1 & 110.2 & 1.82 & 1.82 \\
\hline 2 & 79.9 & 1.96 & 1.73 \\
\hline 3 & 75.1 & 2.01 & 2.14 \\
\hline
\end{tabular}

\section{THE EXPERIMENTAL TESTS}

The experimental tests are applied to the proposed converter with the suggested hybrid control technique in order to verify the real-time practical application of the proposed regulator system. The built experimental set-up of the regulator system is demonstrated in Figure 11.

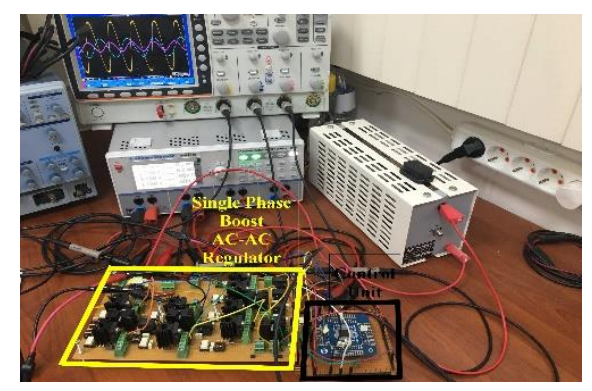

Figure 11. The built experimental set-up of the regulator system

Three different experimental test cases that are given in Table 6 are applied to the regulator system on the experimental set-up. The experimental wave form test results are given in Figures 12-14. The detailed numerical results of the output for the experimental tests are also given in Table 7.

Table 6. Test cases for the experimental tests.

\begin{tabular}{cccc}
\hline $\begin{array}{c}\text { Test } \\
\text { Cases } \\
\text { No }\end{array}$ & $\mathbf{V}_{\mathbf{i}}$ & Output Load $\mathbf{Z}$ & $\begin{array}{c}\text { Desired output } \\
\text { fundamental sine-wave } \\
\text { voltage } \mathbf{V}_{\mathbf{o}} \\
(V)\end{array}$ \\
\hline 1 & & & 70 \\
\hline 2 & $45 \mathrm{~V}$ sine $(\mathrm{f}=50 \mathrm{~Hz})$ & Resistive $\mathrm{R}=15 \Omega$ & 80 \\
\hline 3 & $55 \mathrm{~V}$ sine $(\mathrm{f}=50 \mathrm{~Hz})$ & Inductive $\mathrm{R}=25 \Omega, \mathrm{L}=10 \mathrm{mH}$ & 120 \\
\hline
\end{tabular}

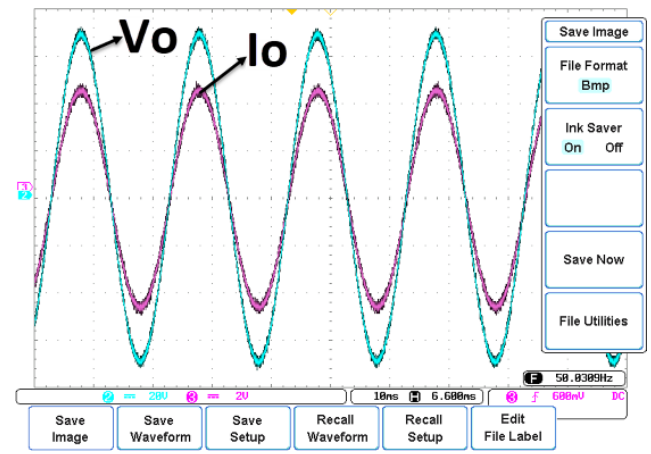

Figure 12. Experimental results for the test case-1 (V/div=A/div for $\left.I_{o}\right)$ 


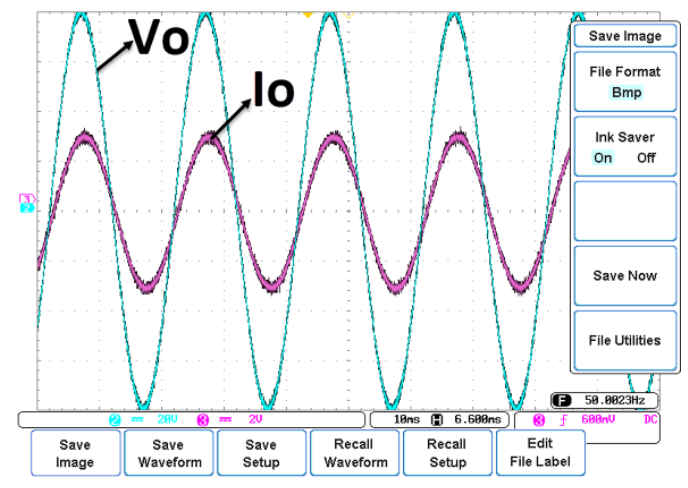

Figure 13. Experimental results for the test case-2 $\left(V / d i v=A / d i v\right.$ for $\left.I_{o}\right)$

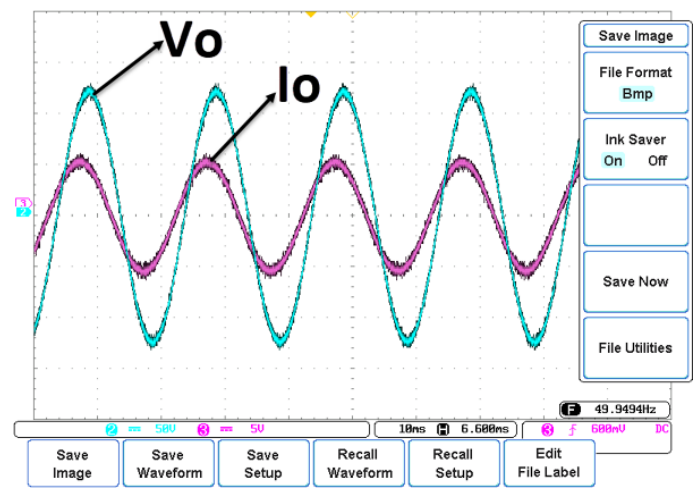

Figure 14. Experimental results for the test case-3 $\left(\right.$ V/div=A/div for $\left.I_{o}\right)$

Table 7. The achieved numerical experimental results of the test cases.

\begin{tabular}{cccc}
\hline \multirow{2}{*}{ Test Case No } & $\begin{array}{c}\text { Obtained Fundamental } \mathbf{V}_{\mathbf{~}} \\
(V)\end{array}$ & $\begin{array}{c}\mathbf{T H D}_{\mathbf{V}} \\
(\%)\end{array}$ & $\begin{array}{c}\text { THD }_{\mathbf{I}} \\
(\%)\end{array}$ \\
\hline 1 & 70.4 & 1.95 & 1.88 \\
\hline 2 & 80.3 & 2.08 & 1.85 \\
\hline 3 & 119.8 & 2.16 & 2.27 \\
\hline
\end{tabular}

The experimental results given in Figures 12-14 and Table 7 prove the experimental validity of the proposed single-phase boost-type AC-AC regulator for providing the desired reference AC sine-wave voltages as close as possible with low THD levels under 5\%. Thus, the wave form results in Figures 12-14 and the numerical results in Table 7 prove that the proposed hybrid control technique is capable of obtaining accurate and efficient active tracking of the reference input voltages also in real-time practical operation of the proposed regulator.

In order to reveal the efficiency of the proposed hybrid control technique on active tracking, a comparative test study is done. In this test study, the proposed hybrid control technique and the standalone PID control are applied to the proposed regulator separately for the experimental test case1. The obtained output voltage waveforms for the mentioned two separate applications are given together in Figure 15. Also, the comparative numerical output THD results of these applications are given in Table 8. 


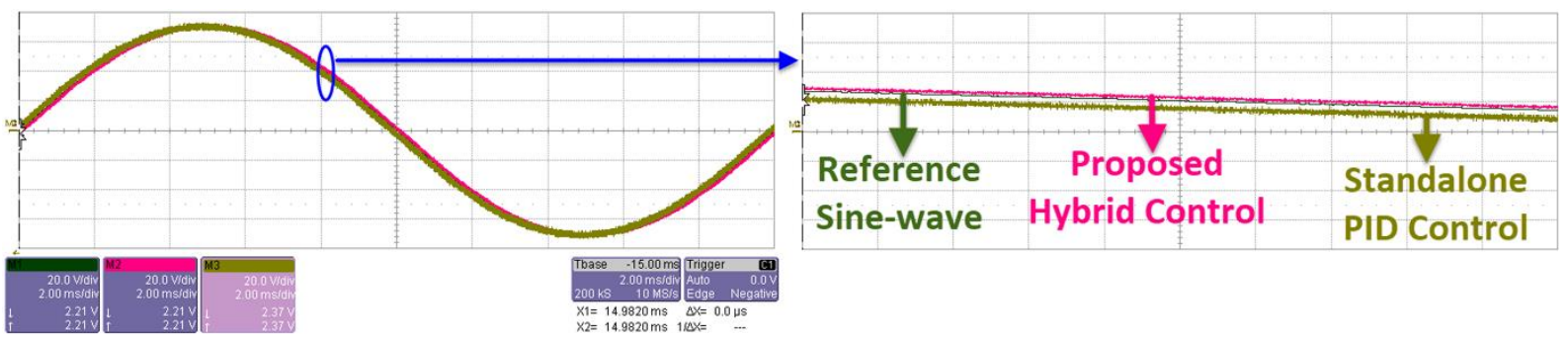

Figure 15. Comparative output voltage $V_{o}$ wave forms of the proposed hybrid control and the standalone PID control for the test case-1 (20V/div, 2ms/div)

Table 8. Comparative THD results of the proposed hybrid control and the standalone traditional PID control on the experimental test cases.

\begin{tabular}{ccccc}
\hline \multirow{2}{*}{ Test Case No } & $\begin{array}{c}\text { THD results of the proposed hybrid } \\
\text { control method } \\
(\%)\end{array}$ & \multicolumn{2}{c}{$\begin{array}{c}\text { THD results of the traditional } \\
\text { standalone PID control } \\
(\%)\end{array}$} \\
\cline { 2 - 5 } & THD $_{\mathbf{V}}$ & $\mathbf{T H D}_{\mathbf{I}}$ & $\mathbf{T H D}_{\mathbf{V}}$ & THD $_{\mathbf{I}}$ \\
\hline 1 & 1.95 & 1.88 & 2.06 & 2.00 \\
\hline 2 & 2.08 & 1.85 & 2.21 & 1.99 \\
\hline 3 & 2.16 & 2.27 & 2.31 & 2.43 \\
\hline
\end{tabular}

As seen from Figure 15, active tracking of the reference output sine-wave voltage is better for the proposed hybrid control technique than the traditional PID-control. This proves the efficiency of the developed CL on supporting the PID controller. The output THD results in Table 8 also prove that the proposed hybrid control technique provides closer sine-wave output voltages with low THD values that are lower than $5 \%$ with high quality.

The proposed single-phase boost-type regulator's efficiency is obtained for different output power rates considering the power rate that is determined in the design criteria. The regulator's efficiency curve is achieved as demonstrated in Figure 16. The proposed regulator has an average 95\% efficiency for loads higher than one third of the designed maximum power rate.

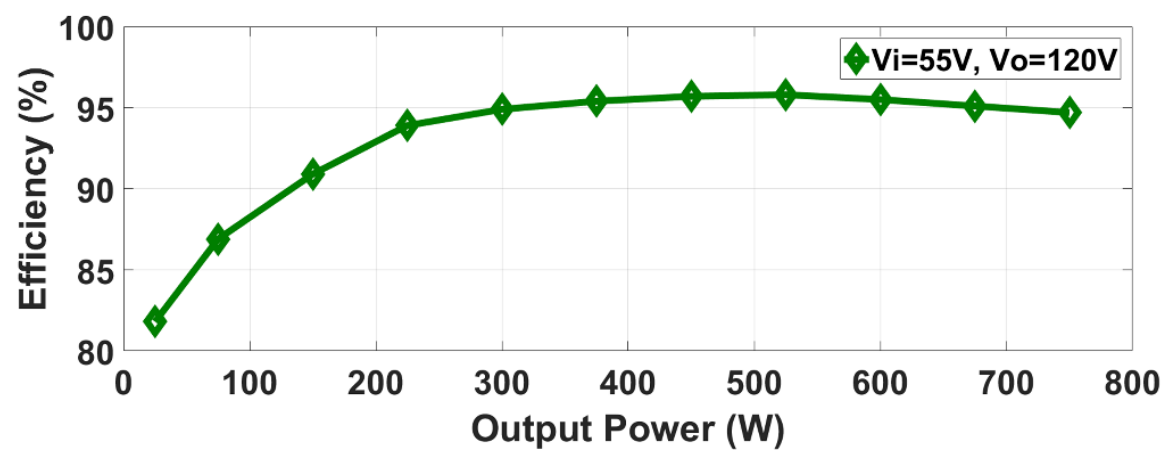

Figure 16. Regulator efficiency curve for different output power rates

\section{CONCLUSION}

In this paper, a single-phase boost-type switch-mode AC-AC voltage regulator is presented with a reduced numbers of components in the topology. A new hybrid control technique is developed for the control of the regulator. The closed-loop PID controller is supported with a newly developed feedforward controller in the proposed hybrid control technique to augment the active tracking of the reference output voltage. In this way, close to sine-wave high-quality output voltage is obtained 
efficiently for both pure sine-wave AC input voltage and AC input voltage containing higher harmonics. Both the simulation and experimental studies are performed for the here described regulator system. The results obtained for both the simulation and the experimental tests prove that the proposed single-phase boost-type switch-mode regulator can produce a desired AC voltage close to the sine-wave for various load and input/output parameters with lower than 5\% THD values.

ACKNOWLEDGEMENTS: The topology and control theory of the proposed AC regulator in the study are patented by the co-author in Austrian Patent Office as "Aktive Netzfilter" (patent no: AT 505460 B1, filed 10.07.2007, applied 15.06.2012).

\section{REFERENCES}

[1] T. A. Naidu, S. R. Arya, A. Al-Durra, and T. H. M. El-Fouly, "Comparative performance of dynamic voltage restorer using adaptive control algorithms with optimized error regulator gains," Int. Trans. Elect. Energy Syst., early access, article no: e12696, 2020.

[2] T. Kandil and M. A. Ahmed, "Control and operation of dynamic voltage restorer with online regulated DC-link capacitor in microgrid system," Can. J. Elect. Comput. Eng., vol. 43, no. 4, pp. 331-341, 2020.

[3] J. You, D. M. Vilathgamuwa, N. Ghasemi, and W. L. Malan, "Analysis and control of integrated DC bus voltage conditioner for cascade power converter system," IEEE 3rd Int. Futur. Energy Electron. Conf. Ecce Asia (IFEEC 2017-ECCE ASIA), 2017, pp. 522-527.

[4] P. Vu, V. T. N. Van, Q. Nguyen, N. Q. Dich, and M. Tran, "Design and implementation of active voltage conditioner in low-voltage distribution system," J. Elect. Syst., vol. 16, no. 4, pp. 569$581,2020$.

[5] D. M. Lee, T. G. Habetler, R. G. Harley, T. L. Keister, and J. R. Rostron, "A voltage sag supporter utilizing a PWM-switched autotransformer," IEEE Trans. Power Electron., vol. 22, no. 2, pp. 626-635, 2007.

[6] S. Subramanian and M. K. Mishra, "Interphase AC-AC topology for voltage sag supporter," IEEE Trans. Power Electron., vol. 25, no. 2, pp. 514-518, 2010.

[7] J. Kaniewski, Z. Fedyczak, and G. Benysek, "AC voltage sag/swell compensator based on three-phase hybrid transformer with buck-boost matrix-reactance chopper," IEEE Trans. Ind. Electron., vol. 61, no. 8, pp. 3835-3846, 2014.

[8] K. Yamamoto, K. Ikeda, Y. Tsurusaki, and M. Ikeda, "Characteristics of voltage sag/swell compensator utilizing single-phase matrix converter," Int. Conf. Elect. Mach. Syst. (ICEMS), 2013, pp. $1863-1868$.

[9] R. P. R De Sousa, N. S. D. L. Marinus, C. B. Jacobina, and N. Rocha, "A unidirectional single-phase AC-DC-AC three-level three-leg converter," IEEE Trans. Ind. Appl., vol. 55, no. 2, pp. 1708-1716, 2019.

[10] L. Yang, H. Zhao, S. Wang, and Y. J. Zhi, "Common-mode EMI noise analysis and reduction for AC-DC-AC systems with paralleled power modules," IEEE Trans. Power Electron., vol. 35, no. 7, pp. 6989-7000, 2020. 
[11] M. Lucanu, O. Ursaru, C. Aghion, and N. Lucanu, "Efficient high frequency single-phase AC chopper,” Rev. Roum. Sci. Techn. - Électrotechn. Et Énerg., vol. 64, no. 1, pp. 69-74, 2019.

[12] M. R. Hajimoradi and H. Mokhtari, "AC voltage regulator based on AC/AC buck converter," 7th Power Electron. Driv. Syst. Technol. Conf. (PEDSTC), 2016, pp. 140-146.

[13] Y. B. Wang, P. Wang, G. W. Cai, C. Liu, D. B. Guo, H. W. Zhang, and B. D. Zhu, "An improved bipolar-type AC-AC converter topology based on nondifferential dual-buck PWM AC choppers," IEEE Trans. Power Electron., vol. 36, no. 4, pp. 4052-4065, 2021.

[14] S. Sakamoto, T. Mishima, and C. Ide, "A phase-shift PWM-controlled ZVS boost full-bridge AC-AC converter for metal-surface high-frequency induction heating applications," IEEE Energy Convers. Congr. Expo. (ECCE), 2016.

[15] M. S. Dall'Asta, I. Barbi, and T. B. Lazzarin, "AC-AC hybrid boost switched-capacitor converter," IEEE Trans. Power Electron., vol. 35, no. 12, pp. 13115-13125, 2020.

[16] F. Yalcin and F. A. Himmelstoss, "A new 3-phase buck-boost AC voltage regulator," Elect. Power Compon. Syst., vol. 44, no. 20, pp. 2338-2351, 2016.

[17] A. A. Khan, H. Cha, and H. F. Ahmed, "A new reliable three-phase buck-boost AC-AC converter," IEEE Trans. Ind. Electron., vol. 65, no. 2, pp. 1000-1010, 2018.

[18] Energylogix. (2021, March 2). Harmonics and IEEE 519 [Online]. Available: http://energylogix.ca/harmonics_and_ieee.pdf.

[19] F. Himmelstoss, “Aktive Netzfilter,” Austrian Patent, patent no: AT 505460 B1, 2012. 